\title{
Diffusivity of phosphorous in olivine revisited: A joint experimental and modeling approach
}

\author{
WILLIAM NELSON $^{1 *}$ JULiA HAMMER $^{1}$, THOMAS SHEA ${ }^{1}$,
} SUMIT CHAKRABORTY ${ }^{2}$

${ }^{1}$ SOEST, University of Hawaii at Manoa, Honolulu Hi, USA wnelson@hawaii.edu (* presenting author)

${ }^{2}$ Institut für Geologie, Mineralogie und Geophysik RuhrUniversität Bochum, D-44780, Germany

Intricate heterogeneities in the phosphorous $(\mathrm{P})$ contents of olivine $[1,2,3]$ are consistent with the observation that $\mathrm{P}$ diffuses slowly in olivine when compared to other elements [4]. This relatively low mobility presents an opportunity to resolve the time scales of magmatic events that trigger rapid olivine growth (and thus P-uptake) via diffusion chronometry. However, application of the sole published $\mathrm{P}$ diffusion coefficient [4] yields timescales that are far shorter than those generated by other chronometers applied to the same mineral or sample [5]. That the published P-diffusion coefficients ( $\mathrm{DP}_{\mathrm{P}}$ values) could be too high is further confirmed by the presence of $\mathrm{P}$ concentration heterogeneities in slowly cooled samples, such as gabbros [2]. As P evidently occupies the tetrahedral site [6], its mobility in olivine may be similar to that of the tetrahedrally-coordinated cation, $\mathrm{Si}$, and thus several orders of magnitude lower than posited by [4].

We approach the problem from two angles. First, we solve for the $D_{P}$ required to match the timescales derived from 2D P concentration maps using $\mathrm{Fe}-\mathrm{Mg}$ interdiffusion in the same crystal. Preliminary modeling of an olivine crystal from Kilauea's $\mathrm{Pu}^{\prime} \mathrm{u}^{‘} \overline{\mathrm{O}}^{`} \mathrm{O}$ eruption zoned in $\mathrm{Mg}-\mathrm{Fe}$ and containing fine lamellae enriched in $\mathrm{P}$ yields a P-diffusion time that matches the $\mathrm{Mg}-\mathrm{Fe}$ diffusion time when $\mathrm{DP}_{\mathrm{P}}=3.26 * 10^{-20} \mathrm{~m}^{2} / \mathrm{s}$. This value is two orders of magnitude lower than previously suggested for $1498 \mathrm{~K}$ : $(10.29 \pm 10.26)^{*} 10^{-18} \mathrm{~m}^{2} / \mathrm{s}$ [4]. In our second approach, we will progressively map the distribution of $\mathrm{P}$ in cut surfaces of natural olivine crystals before and after prolonged heating at magmatic temperatures, and calculate the $\mathrm{D}_{\mathrm{P}}$ that accounts for the observed relaxation. These two methods should provide independent evaluations of P-diffusivity in olivine.

[1]Milman-Barris et al.(2008) Contrib Mineral Petrol 155 739-765. [2]Welsch et al.(2014) Geology 42 867-870. [3]Shea et al. (2016) Geology 44 518-518 [4]Watson et al.(2015) Am. Mineral. 100 2053-2065 [5] Nelson et al. (2019) AGU 2019 Fall Meeting V51F-0114 [6]Buseck et al.(1977) Geochim. Cosmochim. Acta 41 711-740. 